\title{
Treatment of Uncomplicated Falciparum Malaria with Artesunate- Amodiaquine Combination Therapy (ACT) in a Rural Fishing Community in Sierra Leone
}

\author{
Foday Sahr $^{1^{\star}}$, Gevao Sahr $\mathbf{M}^{1}$, Bockarie Alex ${ }^{1}$, Ibrahim-Sayo Emmanuel ${ }^{1}$, Sevalie \\ Stephen ${ }^{1}$, Hanciles Angela ${ }^{1}$, and Gbakima Aiah A $^{2}$ \\ ${ }^{1}$ Department of Microbiology, College of Medicine and Allied Health Sciences, University of Sierra Leone, \\ ${ }^{2}$ Fourah Bay College, University of Sierra Leone, Freetown, Sierra Leone
}

\begin{abstract}
Until recently, Chloroquine was the mainstay for malaria chemotherapy in Africa because it is cheap, safe and practicable for out-patient use. Resistance to this drug has however over the past decade, presented a major public health problem with therapeutic and prophylactic implications. As a response to the emergence of resistance to the commonly used antimalarial drugs, the World Health Organisation (WHO) now recommends the use of artemisinin-based combination therapies (ACTs). We assessed the therapeutic efficacy of oral Artesunate-Amodiaquine hydrochloride combination therapy in the treatment of uncomplicated falciparum malaria in a rural fishing community in Sierra Leone. One hundred and fourteen (114) participants aged 0 - 5 years attending the Outpatient Department of Gbondapi Health Centre were screened for recruitment into the study of which 70 fulfilled the inclusion criteria. Artesunate-Amodiaquine hydrochloride combined drug which passed the general counterfeit test of the Ministry of Health and Sanitation was used in the study. Adequate Clinical and parasitological Response (ACPR) was observed in $97 \%$ of the study population. Mean parasite clearance time in the participants with ACPR was found to be 24 hours (range $24-72$ hours). All $3 \%$ of the treatment failures were observed to be Early Treatment Failures (ETF). Results from the study indicate that Artesunate-Amodiaquine hydrochloride combination therapy is an effective antimalarial drug in a high transmission zone like Sierra Leone, and in the event that the drug is not effective, the results will be evident within one day of commencement of treatment.
\end{abstract}

\section{Keywords: Artesunate-Amodiaquine, Falciparum, Therapy}

Received 23 November 2009/ Accepted 21 December 2009

\section{INTRODUCTION}

Malaria has been reported as the leading cause of death in most countries in sub-saharan Africa with children below five years bearing the most morbidity and mortality (Taylor et al., 1993). Until recently, chloroquine was the mainstay for malaria chemotherapy in Africa because it is cheap, safe and practicable for outpatient use (Sahr et al., 2004). Resistance to this drug and other antimalarial drugs has however over the past decade, presented a major Public Health problem with therapeutic and prophylactic implications (Sahr et al., 2001). There is accumulating evidence that diminished sensitivity of the Plasmodium parasites to these commonly used antimalarial drugs is spreading (Simon et al., 1988; Oduola et al., 1989; Brasseur et al., 1992; Sowunmi and Oduola, 1997), and hence, strategies to prevent further spread and the availability of treatment options are urgently required. One such drug introduced for the treatment of multidrug-resistant falciparum malaria is artemisinin. 
The susceptibility of Plasmodium falciparum to artemisinin has been well established (Elhassan et al., 1993; Von Seidlein et al., 2000), and its effectiveness in the treatment of falciparum malaria in Africa has also been well documented (White et al., 1992; Elhassan et al., 1993; Taylor et al., 1993; Sowunmi and Oduola 1998).

Recent reports suggest an emergence of decreased sensitivity of the malaria parasite to artemisinin when used as monotherapy (Gay et al., 1994; Sahr et al., 2001). As a response to the emergence of such resistance, the World Health Organisation (WHO) now recommends the use of artemisinin-based combination therapies (ACTs) (WHO, 2006). Three such combinations commonly use in Sierra Leone are artesunateamodiaquine, artesunate-lumefantrine and artesunate-sulfadoxime-pyrimethamine

combinations. There is no available data on the efficacy of these combination drugs in Sierra Leone, but limited data collected by the Ministry of Health and Sanitation suggests that failed treatment to these newly introduced artemesinincombinations is very rare (unpublished data). The objective of the present study is therefore to assess the therapeutic efficacy of oral ArtesunateAmodiaquine Hydrohloride combination therapy in the treatment of uncomplicated falciparum malaria in a rural farming and fishing community in Sierra Leone.

\section{PARTICIPANTS AND METHODS Study Site and Population}

The study was conducted in Gbondapi village which is an established fishing settlement located in the Mao Sakrim Chiefdom, Pujehun District in the Southern Province of Sierra Leone. The village is divided into 3 communities - Gbondapi, Mani and Sumbuya and is bordered on the east by the Yakemo Kpukumu Krim and Kpaka Chiefdoms, on the South by the Atlantic Ocean, northwest by Kwamebai Chiefdom and on the North by Panga Krim Chiefdom. Because of the very close proximity between Mani and Sumbuya, and the relatively few participants registered from Sumbuya, all the participants from this community were registered under Mani. Majority of the 5,000 residents speak mende, creole and a few speak English. There is a government assisted health centre in the village that is supervised by a Community Health Officer, with referrals often made to the district Hospital in Pujehun town that is 80 kilometers away. Malaria transmission in this area is high and peaks during the rainy season. The village depends on a few hand-pump wells and unprotected streams for domestic water use, and poorly built pit-latrines for adults while children defecate indiscriminately between houses.

\section{Sample Collection and Examination}

Data was collected from the Primary Health Centre. The Health Centre serves all age groups in the three communities and subjects enrolled for the study were children below 5 years attending the Gbondapi Health Centre. The WHO Protocol (WHO 2003) for the recruitment of participants in therapeutic efficacy trials in high transmission zones was applied. The inclusion criteria were: Children below 5 years, temperature $\geq 37.5^{\circ} \mathrm{C}$, mono-infection with Plasmodium falciparum, parasitemia $\geq 1000$ parasites/ $\mathrm{\mu l}$ of blood and Informed consent from accompanying parents. Participants with severe or complicated malaria according to the WHO classification (WHO 1996) were excluded from the study and treated with parenteral quinine dihydrochloride. ArteunateAmodiaquine hydrochloride combined drug which passed the general counterfeit test of the Ministry of Health and Sanitation was used in the study. Each tablet of Artesunate contained $50 \mathrm{mg}$ Artesunate and each tablet of Amodiaquine hydrochloride contained 150mg Amodiaquine. The test drug was administered orally over a three day period under the direct supervision of Community Health Officer $(\mathrm{CHO})$ in the following dosages as directed by the manufacturers (Guilin Pharmaceutical Co. Ltd. China):

Adults: $\quad 2$ tablets of Artesunate with 2 tablets Amodiaquine hydrochloride 12 hourly for three days

7-13 years: 1 tablet Artesunate with 1 tablet Amodiaquine hydrochloride 12 hourly for three days.

1-6 years: Half tablet Artesunate with half tablet Amodiaquine hydrochloride tablet 12 hourly for three days.

All participants were followed-up on days 1 , $2,3,7,14,21$ and 28 during which the child's general condition was assessed and blood smear prepared for the assessment and demonstration of malaria parasites. 
Axillary temperature of all each participant was also recorded on each of the follow-up days. The response to the test drug was recorded according to the recommendation of the WHO (WHO 1996): Adequate clinical and parasitological response (ACPR), Early Treatment Failure (ETF) and Late Treatment Failure (LTF). Briefly, ACPR was defined as the absence of parasitemia on day 14 irrespective of axillary temperature or axillary temperature less than $37.5^{\circ} \mathrm{C}$ irrespective of parasitemia, without previously meeting any of the criteria of ETF. Therapeutic response was classified as ETF if the subject developed one of the following conditions during the first three days of follow-up.

a) Axillary temperature $\geq 37.5^{\circ} \mathrm{C}$ on day 2 with parasitemia greater than that on day 0 or

b) Axillary temperature $\geq 37.5^{\circ} \mathrm{C}$ on day 3 in the presence of parasitemia or

c) Parasitemia on day $3 \geq 25 \%$ of count on day 0 .
Therapeutic response was classified as LTF if a subject had axillary temperature $\geq 37.5^{\circ} \mathrm{C}$ in the presence of parasitemia on any day from day 4 to day 14 without previously meeting any of the criteria of ETF. All subjects with ETF and LTF were put on quinine sulphate $10 \mathrm{mg} / \mathrm{kg} 8$ hourly for at least five days.

\section{Ethical Clearance}

Ethical clearance for the study was obtained from the Research and Ethics Committee of the Ministry of Health and Sanitation.

\section{RESULTS}

A total of 114 participants were screened for enrollment into the study, of which 70 fulfilled the enrolment criteria. Laboratory data of the participants enrolled into the study is summarized in Table I. The mean age of the participants was 17.2 months and the mean parasite count on the day of enrolment (day 0) was 1264 parasites/ $\mu$ l of blood. The temperature of the participants on the day of enrolment ranged from $37.8-39.2^{\circ} \mathrm{C}$ with a mean of $38.1^{\circ} \mathrm{C}$.

\section{TABLE 1: Laboratory data of participants enrolled in Artesunate-Amodiaquine Hydrochloride Combined Therapy efficacy study in Gbondapi and Mani}

\begin{tabular}{l|l}
\hline & Variable \\
\hline No of subjects screened & 114 \\
\hline No of subjects recruited & 70 \\
$\begin{array}{l}\text { Age of subjects (months) } \\
\text { Mean }\end{array}$ & \\
\cline { 2 - 2 } $\begin{array}{l}\text { Range } \\
\text { Temp on day 0 }\left({ }^{\circ} \mathrm{C}\right)\end{array}$ & 17.2 \\
$\begin{array}{l}\text { Mean } \\
\text { Range }\end{array}$ & 38.60 \\
\cline { 2 - 2 } $\begin{array}{l}\text { Parasitemia on day 0 (Parasites/ } \mu \mathrm{l} \text { of } \\
\text { blood) }\end{array}$ & $37.8-39.2$ \\
\hline $\begin{array}{l}\text { Mean } \\
\text { Range }\end{array}$ & 1264 \\
\cline { 2 - 2 } & $1006-2430$
\end{tabular}

The therapeutic responses of the 70 participants enrolled in the study are summarized in Table 2. All 70 participants completed the 28 day follow up. The mean fever clearance time with the test drug was one day (range 24-72 hours), and the mean parasite clearance time was also 24 hours (range 24-72hours). 
Table 2: Summary of the Therapeutic Response of Participants enrolled in Artesunate-Amodiaquine hydrochloride Combined Therapy Study

\begin{tabular}{|l|l|}
\hline & Variable \\
\hline No enrolled in study & 70 \\
\hline No completed in study & 70 \\
\hline Fever clearance time (hours) & \\
\hline $\begin{array}{l}\text { Mean } \\
\text { Range }\end{array}$ & 24 \\
\cline { 2 - 3 } & $\mathbf{2 4 - 7 2}$ \\
\hline $\begin{array}{l}\text { Parasite clearance time(hours) of children with } \\
\text { adequate clinical response }\end{array}$ & \\
\hline $\begin{array}{l}\text { Mean } \\
\text { Range }\end{array}$ & 24 \\
\cline { 2 - 3 } $\begin{array}{l}\text { No (\%) of subjects with Adequate Clinical Response } \\
\text { (ACPR) }\end{array}$ & $\mathbf{2 4 - 7 2}$ \\
\hline $\begin{array}{l}\text { No (\%) of Subjects with Early Treatment Failure } \\
\text { (ETF) }\end{array}$ & $2(3)$ \\
\hline
\end{tabular}

Adequate Clinical Response (ACPR) to the drug was observed in $97 \%$ of the participants with only $3 \%$ showing treatment failures. According to the WHO classification of treatment failures (WHO 2003), all $3 \%$ treatment failures were observed to be Early Treatment Failures (ETF).

\section{DISCUSSION}

Because resistance to the commonly used antimalarial drugs is a global problem, Artemisinin-based combination therapies (ACTS) are now the first-line therapies in most malariaendemic countries. The commonly used artemesinin-based combination therapies in the treatment of uncomplicated falciparum malaria are Artemether-mefloquine and Artemetherlumefantrine (WHO, 2006). Another available Artemesinin combination is the ArtesunateAmodiaquine, which is recommended by the Ministry of Health and Sanitation of Sierra Leone as the first-line drug in the treatment of uncomplicated falciparum malaria.

The results of this study suggest that ArtesunateAmodiaquine combined therapy is highly efficacious in the treatment of falciparum malaria in Sierra Leone as evidenced by the $97 \%$ clinical response obtained. Recent clinical and molecular studies suggest the emergence of ACT-resistant Plasmodium falciparum infections in the Cambodia-Thailand border area, were the standard ACT is Artesunate-mefloquine combination (Wongsrichanalia et al., 2000). It was suggested that treatment failures observed in that study might be due to the high-level mefloquine resistance, as mefloquine was used as monotherapy in the treatment of falciparum malaria long before the introduction of ACT.

Sahr et al. (2001) have reported 4 cases of apparent drug failure in Sierra Leone with the use of Artesunate as monotherapy. The four cases described indicate that although Artesunate is a safe alternative drug to Chloroquine, resistance to it is slowly emerging on the African continent. Using the criteria of the World Health Organisation in the classification of treatment failures, no late treatment failures (LTF) were observed within our study population. This indicates that in the event that ArtesunateAmodiaquine combined therapy is not effective, the result will be known within a day of commencement of therapy. The Artemisinins are characterized by a rapid reduction of parasitemia which begins almost immediately on commencement of treatment with complete clearance usually occurring within 48 hours. Several reports suggest that radical cure can be achieved with the Artemisinins when they are combined with other antimalarial drugs (Looareesuwan et al., 1992; Nosten et al., 1994; Prince et al., 1995; Von Seidlein et al., 2000).

Results of a survey conducted in the capital Freetown among pharmacies on the sale of antimalarial drugs revealed that Artesunate ranks high in the list with most of the drug sold without prescriptions (Sahr et al., 1999). 
It is thought that if the unregulated use of Artesunate or its combined antimalarial drugs continues, there is a high tendency of enhancing the development of resistance to the drug among the Sierra Leonean population. It is therefore recommended that measures are put in place by the Ministry of Health and Sanitation to restrict the distribution and sale of Artesunate-combination drugs so as to reduce the tendency of the development of resistance to the drug.

\section{ACKNOWLEDGEMENTS}

We wish to thank the Elders of Gbondapi Village for allowing us into the community and for the abundant support rendered to our survey team. This work was done with funds provided by MIM/TDR. (Project ID A60045).

\section{REFERENCES}

Brasseur P, Kouamouo J, Moyou-Somo RS and Druilhe P (1992). Multi-drug resistant falciparum malaria in Cameroun in 1987 - 1988: Stable Figures of Prevalence of Chloroquine and Quinine Resistant Isolates in the Original Foci. Am J Trop Med Hyg. 46: $1-7$

Elhassan IM, Satti GH, Ali EA, Fadul I, ElKhalifa AA, Abederlrahim AM, Ming $C$ and Theander TG (1993). The Efficacy of Artemether in the Treatment of Plasmodium falciparum Malaria in Sudan. Soc Trans R Soc Trop Med Hyg. 87: 685 -686 .

Looareesuwan S, Viravan C, Vanijanonta, Wilairatana $\mathrm{P}$, Suntharasamai $\mathrm{P}$, Charoenlarp $\mathrm{P}$, Arnold K, Kyle D, Canfield C and Webster K (1992). Randomised trial of Artesunate amd Mefloquine alone and in sequence for acute uncomplicated falciparum malaria. Lancet. 1: 821-824.

Nosten F, Luxemburger C, Ter Kuile FO, Woodrow C, Eh JP, Chongsuphajaisiddhi T and White NJ (1994). Treatment of Multi-drug Resistant Plasmodium falcparum with 3-day
Artesunate- mefloquine Combination. $J$ Infect Dis. 170: 971-977.

Oduola AMJ, Moyou-Somo RS, Kyle DE, Martin SK, Gerena L and Milhous WK (1989). Chloroquine Resistant Plasmodium falciparum in Indigenous Residents of Cameroun. Trans $R$ Soc Trop Med Hyg. 83: 308-310.

Prince F, Nosten F, Luxemburger C, Khan AM, Chongsuphajaisiddhi T and White NJ (1995). Artesunate versus Artemether in Combination with Mefloquine for the Treatment of Multidrug Resistant Malaria. Trans Royal Soc Trop Med Hyg. 89: 523 - 527.

Sahr F, Gbakima AA, Willoughby VR, Balogun T and Bockarie MJ (2004). Assessment of the Therapeutic Efficacy of Chloroquine and Sulphadoxime-pyrimethamine in the Treatment of Uncomplicated Plasmodium falciparum Malaria in Sierra Leone. J Pure \& Appl. Sci. 9: 89-92

Sahr F, Willoughby VR, Gbakima AA and Bockarie MJ (2001). Apparent Drug Failure Following Artesunate Treatment of Plasmodium falciparum Malaria in Freetown, Sierra Leone: Four Case Reports. Annal Trop Med Paras. 95: 445-449

Sahr F (1999). Assessment of the Therapeutic Efficaacy of Oral Chloroquine in the Treatment of Unconplicated Falciparum Malaria in Freetown, Sierra Leone M.Sc. thesis, University of Sierra Leone (Unpublished).

Sahr F, Morgan HG, Wiloughby VR and Gbakima AA (2004). Efficacy of Chloroquine in Childhood Uncomplicated Malaria at Primary Health Care Level. J SL Med Dent Assoc. 8: 54-60

Sowunmi A and Oduola AMJ (1998). Viability of Plasmodium falciparum In vivo: Comparison of the Effects of Artemether and Sulphadoximepyrimethamine. Europ J Clin Pharm. 5: 221 - 226 
Taylor TE, Wills BA, Kazembe P, Chisale M, Wirima JJ, Ratsma EY and Mohyneur ME (1993). Rapid Coma Resolution with Artemether in Malawian Children with Cerebral Malaria. Lancet. 1: 661-662

Von Seidlein L, Milligan P, Pinder M, Bojang K, Anyalebechi C, Gosling R, Coleman R, Ude Jl, Sadiq A, Duraisingh M, Warhurst D, Alloueche A, Targett G, McAdam K, Greenwood B, Walraven G, Olliaro P and Doherty T (2000). Efficacy of Artesunate plus pyrimethamine-sulphadoxime for Uncomplicated Malaria in Gambian Children: A Double-Blind Randomized, Controlled Trial. Lancet.: 355-357
World Health Organization (2003). Assessment of Therapeutic Efficacy of Antimalarial Drugs for Uncomplicated falciparum Malaria in Areas with Intense Transmission. WHO Geneva: Pp: 5-12

World Health Organisation. Position of WHO'S Roll Back Malaria. Department on Malaria Treatment Policy. Available at www.who.int/malaria/docs/who apt position.htm

Wongsrichanaliai C, Thimasarn $\mathrm{K}$ and Sirichaisinthop J (2000). Antimalarial Drug Combination Policy: A Caveat. Lancet. 355: 2245 -7 . 